\title{
Feminist perspectives on good governance in sport
}

\section{It is the care that guides the doing}

\author{
Inge Claringbould, Annelies Knoppers, \\ and Ramon Spaaij
}

\section{Introduction}

From a theoretical and empirical perspective (see other chapters in this volume) a lot of thought is given to 'good governance' both within and outside sport. Unfortunately, feminist perspectives have rarely been applied to the notion of good governance (Merry, Davis \& Kingsbury 2015; Parent \& Hoye 2018). Attention is paid to feminist theories in sport policy, such as good governance, primarily when the subject matter is gender (Knoppers \& McLachlan 2018). In contrast, the results of a scoping review of research in the area of sport governance by Parent and Hoye (2018) reveal that gender is not a topic directly associated with principles of good governance. Although studies have been published that focus on the importance of gender quotas on sport boards or on the need for gender equity (Henry \& Lee 2004), the need for feminist perspectives on the subject of good governance are not mentioned.

Feminist perspectives often question positivist notions of objectivity and truth, and therefore also the neutrality of good governance. Ideas about 'good governance' are usually drawn up and executed by persons with relatively high levels of freedom, rights and influence. These ideas are therefore not neutral but reflect the social positions of those who created norms about good governance. This may mean that underlying power relations between groups involved in doing good governance remain hidden. A feminist perspective might analyse who performs practices of good governance, how and from what interest or position, and what the consequences of these practices are in terms of reconstructing and reproducing power relations. For example, Puwar (2004) describes how white male bodies remain unmarked in most public spaces, and thus continue to dominate and set norms without being questioned about their white male dominance. They tend to think their stance is neutral, while non-white and/or female bodies are constantly supervised and scrutinised for how they position themselves in society. They are thus marginalised when norms and standards are created.

These processes have an enormous impact on everyday interactions and on the ways policies, management and institutions are constructed. Connell (2009) sees such a worldwide 'gender order' as a continuing pattern. Substantially harming 
women's rights and input in society and continuing white heterosexual men's voices and perspectives as dominant in all societal domains.

The aim of this chapter is to elaborate feminist perspectives that can be applied in conceptualising and realising good governance and thus shed a new light on the current dialogue on good governance in sport. The central question that guides this chapter is: How can feminist theory contribute to scholarly and policy debates on good governance in sport?

The following sections elaborate and discuss two particular feminist approaches.

The first is standpoint theory attributed to the work of Dorothy Smith (1987, 1990). We draw on this perspective to show that the question of what is 'good' in good governance can never be answered in a universal way. Feminist standpoint theory offers a further deepening of this perspective, since it is based on the assumption of positionality of all forms of knowledge and experience, thereby calling into question the neutrality of knowledge and science. This perspective not only challenges the neutrality of good governance criteria, but also stresses that ignoring different voices and standpoints of stakeholders, undermines the 'good' in good governance.

The second approach is 'ethics of care', derived from the work of Carol Gilligan (1982). We choose this perspective to present an alternative to exclusionary notions of 'good' governance. Ethics of care offers such an alternative. Here 'care' is an ethical principle, reflecting an underlying value and way of doing, which can be applied to reflections on the 'good' in good governance. Both perspectives may offer alternative guidelines for current conceptualisations of good governance. Contrary to other (dominant) conceptualisations of good governance, these perspectives take marginalised ideas into consideration and assume organisations have an ethical obligation to do so. Such feminist perspectives may not only be seen as an ethical consideration for doing good governance, but also as an overarching principle and guarantee for practicing good governance.

\section{Theoretical perspectives}

Although feminist perspectives are so diverse that they can hardly be summarised under one rubric, they all have in common that they question positivist notions of objectivity and truth (Stoetzler \& Yuval-Davis 2002). They assume that what is understood to be universal knowledge and truths are presented and accepted as common sense and neutral; consequently, the gendered and hegemonic basis of such knowledge remains unmentioned and marginalised experiences and other ways of knowing are easily overlooked. In this way, existing social inequalities are effortlessly reproduced and mask and legitimate a hegemonic masculinist positioning (Stoetzler \& Yuval-Davis 2002). As Haraway says: "Despite their differences, they [feminist perspectives] have all challenged the god-trick of seeing everything from nowhere" (Haraway 1991, p. 189), with which she criticises the neutrality of knowledge and states that knowledge is always linked to a certain position. Moreover, she indicates that knowledge is situated, but not necessarily 
subjective. Rather, positionality offers the opportunity to acquire certain knowledge that is related to the power position someone has in society.

The relevance of feminist perspectives on good governance therefore, is that they question the neutrality of good governance criteria, and offer insight into power positions and processes in the creation of these criteria.

\section{Feminist standpoint theory}

Although standpoint theory may have originated in the work of Hegel and Marx, who portrayed the views of unequal groups (social classes) in society (Hekman 1997), feminist representatives of standpoint theory have focused on gender inequality. Feminist standpoint theory essentially posits that all knowledge and truths are produced from multiple standpoints. Smith (1997) said: "We know as a matter of doing" (p. 395). She denies universal and neutral considerations, and assumes that social situations fundamentally determine the knowledge individuals acquire and thus the way they are positioned/position themselves in society. Feminists such as Dorothy Smith (1987, 1990), Nancy Hartsock (1983), Patricia Hill Collins (1990, 1997), Donna Haraway (1991) and Sandra Harding (2004), have used this perspective to show how knowledge is anchored in gender. Subsequently they broadened the issue to other social groups, based on race, social class and other social factors, and illustrated how the prevalence of dominant standpoints can serve as the basis for maintaining social and structural inequalities.

\section{Positionality}

Standpoint theory assumes that people acquire knowledge from a variety of societal positions. Individuals are positioned in different ways based on how they are socially categorised in terms of power relations such as gender, race, (dis)ability, sexuality, etc.

This means that taking a position pertains to the physical presence of the body and to the material layout of the space. Someone is physically part of a setting and is therefore always part of a local practice in which positions relate to each other and realise institutional power structures (Puwar 2004). For example, the position of a black female speed skater is very different from that of her white female trainer, even when they are in the same ice rink. They not only have different positions, but will have different experiences and perceptions of what happens in the space as well, due to their history/experiences of being black/white or woman/man. Hartsock (1983) asserts that such experiences limit an understanding of social relations, because reality will be perceived differently as local practices and positions differ. Collins (1997) gives the example of a black feminist academic who is in the unique position that she acquires knowledge from two standpoints: the privileged academic world and also that of black women. She originates from a marginalised group, but operates in the field of a dominant group although she may still be also marginalised within that dominant group. Puwar (2004) calls such a position a 
'space invader'. Collins' social position meant she gained knowledge of underlying power processes associated with both standpoints (dominant and marginalised). These multiple positions enabled her to develop a strategy to survive within the academic world. In contrast, non-marginalised groups tend not to need or develop such awareness or knowledge. Members of non-marginalised groups tend to identify more often with the assumption of neutrality of knowledge since they are generally not aware of their dominant position; they see it as obvious or as common sense.

Standpoint theorists are convinced that not one group can claim neutrality, since all knowledge is situated. Therefore, assumptions about the neutrality of knowledge will mainly contribute to the maintenance of a hegemonic standpoint. Ignoring the partiality and situatedness of knowledge, by labelling it as neutral, also means depriving those marginalised groups of having a voice in society.

\section{Situated knowledge}

People come to knowledge by participating in social processes, so these (local) settings determine what kind of knowledge and experiences people acquire. Standpoints may not be uniform even in the same setting, but depend on the social and cultural context (Stoetzler \& Yuval-Davis 2002). Settings therefore do not have the same meaning for participants, since social groups may acquire different knowledges about a situation due to their own position (Stoetzler \& Yuval-Davis 2002). People who share the same location, for example, may have completely different experiences and knowledge of a situation, dependent on their power position: if the person serves coffee or is giving a lecture; is a black male athlete or a white female athlete listening to a speaker; is a promising young academic or an older person taking care of the operation of devices. All gain different knowledge about who is present in the space, who has the right to speak about what is happening there. In other words, social location and standpoint cannot be reduced to each other but people generate situated knowledge through their interpersonal interactions.

Situated knowledge is perceived and experienced differently depending on the positions someone takes. Positions of individuals or groups may be diverse, intersectional, contradictory and subject to change. Each position has major consequences for the restraints or freedom of action that accompany it, and for the meanings they assign to the situation. Consider a 14-year-old elite gymnast who is aggressively manipulated by her male coach to perform exercises that are physically painful. The gymnast is afraid her sport career will suffer if she does not always obey his instructions. How differently do both experience the space? While he may appropriate the situation due to his position, she feels constantly threatened, because of the way the setting is organised. Her knowledge of what happens in the space is completely different from his. Smith (1990) has defined the settings or situations as:

"The actualities of our everyday world are already socially organised. Settings, equipment, environment, schedules, occasions, and so forth, as well as our 
enterprises and routines, are socially produced and concretely and symbolically organised prior to the moment at which we enter and at which inquiry begins" (p. 23).

\section{Standpoint theory}

Standpoint theory focuses on the social conditions and interactions that construct standpoints of different groups. As Hartsock (1983) states, these groups have material conditions that structure and limit their understanding and knowledge of standpoints and interactions.

Although standpoints are developed over time, they are not essentialist nor a given. For example, speed skating has predominantly been a white sport, which does not mean that it will always that way. Consequently, standpoints in the field of sport about speed skating and race are also subject to change. Standpoints are embedded in a structure-agency perspective. They refer to ethical, institutional and political constructions of groups having shared histories that may be characterised by long standing patterns of gender, class and/or racial marginalisation on the one hand and they shape individual life-experiences and practices on the other (Weeks 1998). Collins (1997) uses this structure-agency perspective to argue that not the individual but the group serves as a unit of analysis of a standpoint. Collins stresses that individuals belonging to corresponding social groups may share similar experiences, but there is at the same time always room for individual agency due to multiple and/or intersectional positionalities. "Although standpoints construct and shape experiences and perception of individuals, they do not determine them in terms of causality and predictability" (Collins 1990, p. 326).

According to Collins (1990) criteria for social groups, such as race, gender, age are not descriptive categories of identity, but elements of a social and political power structure. In other words, social criteria are used to create social groups and the power relations between them. Standpoints become visible almost everywhere in the public domain, for example in sport and recreational facilities, health care systems and education. Changes herein may take place in relation to broader societal changes and/or as a result of policy measures and/or of social political movements.

Stoetzler and Yuval-Davis (2002) stress that knowledge from dominant/hegemonic standpoints need to be explored and made explicit, since most political decisions that affect the largest number of people are taken from these hegemonic standpoints. This and views from the margins should be taken into consideration when we apply standpoint theory to a critical analysis of good governance in sport.

\section{Power}

Standpoint theory was conceptualised by Collins (1997) as a perspective that shows how knowledge always remains central to systems of power that are to the advantage of the interests of dominant groups in society. According to 
Hartsock (1983) dominant groups create positions of power by labelling their perspective as 'real' and rejecting or ignoring other definitions. After all, dominant groups have an interest in suppressing or replacing certain knowledge of subordinate groups, because this rejection gives them the opportunity to continue and control their own dominance.

Smith (1990) asserts that there is no clear division between dominant or marginalised groups since individuals may represent multiple standpoints. People typically may have no trouble defining themselves as marginalised, while at the same time contributing to the marginalisation of others. For example, white women do not always realise the privileges they have compared to black women. Since Collins (1990) assumes that each group has knowledge of, and shares knowledge from its own point of view, that knowledge is never complete, nor neutral, but each has its own partial perspective on reality. This partial knowledge is therefore essential for their position in society. After all, knowledge is positional. The multiplicity of standpoints and their associated knowledge gives people the opportunity to understand other standpoints, yet always from a person's own standpoint. Expressing knowledge without having a suitable position is usually less credible and convincing, for example when a man talks about what it is like to be a woman.

In summary, standpoint theory is very helpful to analyse and make explicit the interests and positions of those involved in and/or excluded from doing good governance. However, this perspective does not inform the ethics necessary for doing good governance.

\section{Ethics of care}

In social science, philosophers have focused on the question of which ethical principles people should hold in order to create a just society (e.g. Rosenberg 2016). Ethics of care can be seen as such an approach.

\section{Ethical principles}

Ethics are often based on principles, or combinations thereof. These principles may emphasise individual autonomy, rights and obligations, call attention to pragmatism, or stress the need for social contracts. Kant for example, assumes the autonomy of a person and a person's rights and obligations constitute a basic principle for a just society.

Kant (Morrell 2006; Rosenberg 2016) assumes that there are certain moral rules that are a priori and universally true. He argues that one should never use human beings as a means to a certain goal, but should treat them as autonomous persons.

In contrast, Mill (Morrell 2006; Rosenberg 2016) focused on the usefulness and consequences of decisions as basic principles for a just society. He believes that the answer to moral questions should be weighed based on their usefulness (such as happiness, satisfaction, well-being) to those involved. In that case, the greater the general advantage of an action, the better it is. Regardless of whether such 
considerations of utility can be made neutrally/impartially, they may violate people's autonomy. Finally, Rawls (Rosenberg 2016) assumes that a just society should be based on a social contract, a mutual consent. This is based on the so-called 'veil of ignorance', the principle that an agreement is a just agreement, when the outcome is based on a consensus between actors when they do not know in advance what position they will occupy. For example, how could the question be answered whether it is right that men as trainers in elite sport earn much more than women with equal qualities without taking gender positionality into account? Of course, this situation is fictitious because every person involved knows their position, but the fictitious situation means that an agreement or contract can be reached that is acceptable and just to everyone involved, because all conceivable positions can be taken into account. In such a situation Kant would probably plea for equal payments, given the assumed equal autonomy of both men and women, while Mill would probably look at the consequences of such a decision for the benefit of most people involved. In other words, the decision on what 'good' is, is taken differently based on different ethical principles and considerations.

However, these three principles (autonomy, benefit and justice) are not the only possibilities for ethical guidelines. A fourth feminist principle named 'ethics of care' (Gilligan 1982) has evolved as an ethical theory since the 1980s, although it has probably implicitly guided many people's actions throughout history.

\section{Ethics of care}

Ethics of care distinguishes itself from principles of autonomy, benefit and justice by emphasising concrete human relationships instead of abstract principles that enforce ethical actions and decisions (Baier 1994; Benhabib 1992). "While an ethics of justice proceeds from the premise of equality - that everyone should be treated the same - an ethic of care rests on the premise of nonviolence - that no one should be hurt" (Gilligan 1982, p. 174). In the 1970s, Gilligan developed this emphasis in response to the stepwise/phase model of moral development developed by Lawrence Kohlberg. He asserted that an individual has reached maturity when s/he can see moral issues in terms of rights and rules. Gilligan argued that Kohlberg's model was written from a male perspective on morality. In her research, Gilligan discovered that women and men generally interpret moral problems differently. Women may see a "moral problem as a problem of care and responsibility in relationships" as opposed to men who may see it "as one of rights and rules" (1982, p. 73). According to Gilligan, women's positionality means they often approach moral issues in terms of empathy and compassion, and men's positionality means their approach to issues is often allied with rationality and logic. Her research led Gilligan to question the assumed neutrality of moral principles. She explicates that 'female' values and considerations were missing in the existing discussions on ethical behaviour.

Gilligan's ethics of care has been criticised however. An ethics of care pertaining only to women reinforces the traditional image and stereotype of women as being 
caring and empathetic. Gilligan's work was also seen as essentialist (Grimshaw 1986; Tong 2009) and her methods deemed weak (Greeno \& Maccoby 1986). The idea of caring has also been critiqued for being too diffuse to be useful and subject to various interpretations (Broughton 1983).

The idea of an ethics of care has also received support, however, due to the realisation that qualities associated with women were generally underestimated and devaluated in society (Tong 2009). Others (Bartky 1990; Kittay 1999) stated that care and the ethics of care could have a broader social meaning and should no longer be labelled as a typical feminine quality, as opposed to masculine qualities, but rather as a responsibility of men and women embracing an ethics that should be expressed in both the private and the public/corporate sphere. An ethics of care assumes everyone is part of webs of relationships rather than being an independent human being. As such, ethics of care is assumed to serve as an addition or correction to existing perspectives (Bartky 1990; Tong 1993). An ethic of care therefore centres relationships in contrast to common, often masculinised, notions of the self as an autonomous individual (Machold, Ahmed \& Farquhar 2008).

Ethics of care has further been developed by others such as Nel Noddings (1984), Virginia Held (1993, 2006) and Joan Tronto (1993). Held (1993, 2006), Tronto (1993) and Sevenhuijsen (2003) indicate that ethics of care not only applies to interpersonal relationships, but also to the social and political domain making it applicable to human relationships in the public sphere including the development of ideas about good governance in organisations (e.g. Machold, Ahmed \& Farquhar 2008). In sport, ethics of care has been applied as a theoretical framework in sport for development studies (e.g. Debognies, et al. 2019). In these studies, the principle of ethics of care was used to challenge the common top down management of sport programs and their assessment criteria based on effectiveness and efficiency. An ethics of care means relational processes are chosen as the starting point for the (co-)construction and assessment of projects. After all, care can only be realised in social relations.

\section{Beyond Gilligan}

Although 'ethics of care' can be seen as an ethical obligation within relationships (Noddings 1984), it is based on daily moral experiences and problems. Noddings emphasised that the provision of care comes from ethical considerations, from the source of compassion, based on relationships. The correctness of our actions is therefore essentially based on the care for others in a broad sense. It is not based on abstract and generalised notions of equality, equity and relationships "but situates caring for others in relationships in actual situations, in specific contexts, and takes cognizance of feelings and emotions in moral reasoning" (Machold, Ahmed $\&$ Farquhar 2008, p. 670).

Ethics of care is best expressed "(...) as an activity, the activity of care" (Tronto 1987, p. 648). Tronto (1993) further distinguishes between four phases of care. 
The first phase concerns attentiveness: recognising the need and necessity for care. The second concerns responsibility or taking responsibility for providing care. The third is about competence; that is, offering the right expertise for the provision of care. The final phase is the responsiveness phase, in which the care recipient responds to the care received. Tronto assumes that these four phases must be properly connected to fulfil care in an ethical sense.

Ethics of care is essentially not an isolated criterion, but rather an underlying organisational persuasion, responsibility, commitment and form of action that is lacking in so many (sport) organisations. Steward (2020) writes in her Black feminist critique about the logics of higher education institutions' response to COVID-19: "Institutions are bureaucratic and care is not the ethic of institutions; the ethic of the institution is productivity and preservation" (Steward 2020, p. 5). This 'logic' may also count for sport organisations. The use of an ethics of care could therefore support executives and board members of sport organisations in their thinking about new logics of good governance and the legitimacy of their action.

\section{What constitutes good governance}

The question of 'what is good governance' is essentially based on what one should or should not do in governance, a question that generates normative answers based on ethical principles. Although the question in itself thus includes elements of both ethical reflection and the search for practical answers, when it comes to 'good governance' in current discussions this question seems to focus on defining indicators (Davis, Kingsbury \& Merry 2015). In many ways, governance is based on laws, rules and norms about how to act in certain situations. However, ideas and regulations change over time, which implies that the ways in which laws, rules and standards must be applied are continuously discussed and renewed.

This brings us to the question: Is there such a thing as a basic principle or a moral standard from which to determine what 'good governance' entails?

\section{Standpoint theory and good governance}

From the perspective of standpoint theory, thinking about current criteria for good governance would focus not so much on the criteria in themselves (such as accountability, transparency, efficiency, effectivity, equity, democracy, responsibility: e.g. Dowling, Leopkey \& Smith 2018; Henry \& Lee 2004), but rather to how such guidelines for good governance can be measured and formulated as uniform, neutral and objective. From a feminist standpoint perspective, criteria currently used for 'good governance' are always linked to a certain viewpoint or standpoint, and therefore depend on different backgrounds and power positions of those involved in creating criteria for good governance. Feminist would frame criteria for good governance as partial knowledge, and criticise them for suggesting they are uniform and universal and for not linking them to a specific 
standpoint. If the positioning of knowledge from which these principles originate is hidden, good governance is formulated as neutral and generally valid and strengthens those in dominant positions.

This assumed neutrality enables dominant groups to dismiss other knowledge, e.g. from marginalised groups as being subjective and therefore invalid (see the introduction by Geeraert in this volume). Standpoint theory is a powerful approach to understand, analyse, discuss and criticise the so-called neutrality of actions of good governance. The contribution of this theory to good governance, therefore is that it would obviously take the voices of marginalised groups and underlying power processes into account in the development of policy for good governance. However, this perspective does not address guiding principles for doing 'good' governance in various situations, as Carol Gilligan (1982) does with her 'ethics of care'.

\section{Ethics of care and good governance}

Ethics of care is a moral and idealistic position and at the same time a relatively new guideline for the way governance is done. Ethics of care may be defined as a relational, situational and contextual practice of care within the domain of governance matters (Surie \& Ashley 2008). It is also an important correction of the dominance of technocratic, abstract and rationalist thinking, so often expressed in terms of advances and utility that tends to dominate public discussions of good governance (Merry, Davis \& Kingsbury 2015). The implementation of ethics of care as a practice for good governance requires a deeper understanding of situations, through self-reflection and dialogue about institutional contexts, standpoints, interests and asymmetry of power relations. Ethics of care focuses on the ethical principle of "care" and assumes that this principle guides the 'doing' in all cases. It "recognises a multiplicity of actual and potential relationships with varying degrees of asymmetry of power distribution, within which there is an obligation of care" (Machold, Ahmed, Farquhar 2008, p. 673).

Former considerations about good governance (criteria as mentioned above) are still valuable and do not necessarily need to be replaced by ethics of care. Rather, an ethics of care can be seen as an overarching and guiding moral principle that ensures people are not exploited or taken advantage of in unequal power relationships (Machold, Ahmed, Farquhar 2008; Morrell 2006) or vice versa, that people will not abuse public services. For example, the stress on achievement in sport should never lead to the abuse of athletes. Their voice should be heard through dialogue (standpoint theory) and should be taken into account and responded to (ethics of care). In other words, ethics of care is much more than a set of criteria for doing good governance. It is based on a web of relationships in which 'care' can be seen as an underlying life/organisational attitude, on the basis of which more or less continuously changing laws, rules and standards can be calibrated or adjusted. Standpoint theory assumes multiple standpoints are possible and can be taken into consideration through dialogue. 


\section{Reflection}

Most governance theories tend to overlook and/or continue to marginalise the construction of gender and other societal (e.g. racial, social class) inequalities all of which constitute societies. This chapter on feminist perspectives on good governance stressed the importance of the representation and integration of these standpoints into good governance. Standpoint theory stressed that dominant standpoints tend to define their perspectives as neutral, general and in everyone's interest, and may thus oppress marginalised standpoints. Additionally, ethics of care showed that a focus on formal rules, criteria and measures to do good governance is not enough. Ethics of care applies to every situation and deeply supports the governance of democratic societies to survive and thrive. Therefore, it is questionable whether 'good governance' can be realised as being 'good' enough, as long as the power practices of dominant groups continue to prevail without being subject of discussion about whose interests are at stake.

Yet, it is important to recognise that the perspectives outlined here involve dilemmas. Perspectives that contribute to the realisation of good governance should always involve the representation of different standpoints, including marginalised standpoints. Yet, it is not always easy to determine whether all relevant standpoints are included/heard.

In a similar way, ethics of care can be used as an ethical base/principle for the construction and implementation of good governance, but the dilemma is: what do care and the responsibility for care mean? After all, the provision of care is complex and context dependent. Therefore, different care needs and care responsibilities can be defined from different standpoints. Answering these questions is part of the dialogue and assumes a universal answer will not emerge.

Collins (1997) argues that hierarchical organisations easily end up in a dynamic of mutually opposed relationships, where a dialogue focusses on being right, instead of mutual care. She said: "Within hierarchical power relations, it seems reasonable that groups disadvantaged by systems of power might see their strength in solidarity and collective responses to their common location and subjugation. In contrast, it seems equally plausible that those privileged by these types of group placements might want to do away with notions of the group altogether, in effect obscuring the privileges they gain from group membership" (Collins 1997, p. 380).

In such an organisation a dialogue may take place, but since the positions are characterised by conflicting interests, mutual care is absent. In other words, although dialogue is crucial for understanding different points of view, there is still a risk that mutual care will be ignored or neglected.

However, the aforementioned dilemmas should never be a reason to solve problems in a general and instrumental way and not conduct a dialogue from various standpoints. After all, the absence of a multi-voice dialogue suggests that everyone should adhere to rules, laws and manners, while the dominant standpoint only represent the interests of a few. Consequently, good governance continues to be determined by those in positions of power in society. 


\section{Conclusion}

Yuval-Davis (2011) describes the concern of care as an openness and awareness of individuals and institutions that influences compassion, avoiding harm, and sustaining relationships and affects public life. Since ethics of care guides the dialogue this principle is of crucial importance. While the dialogue is a practical opportunity to achieve mutual understanding of different positions, ethics of care represents the intention of mutual understanding and accordingly, acting on this basis. Such an approach operates at both the structural (institutional) level, and the individual. Ethics of care may also be seen as an overall life attitude for those involved in doing good governance. Yet, caring assumes the understanding of social positionality. The merging of standpoint theory with ethics of care may be seen as an alternative to the current, so-called 'neutral' focus on rational thinking, universal indicators for political decisions or technological solutions elaborated by experts in the field. Good governance should always be considered from the perspective of different standpoints and within an 'ethics of care', since care should under all circumstances guide the doing.

\section{Implications for scholars}

Both feminist perspectives on good governance elaborated in this chapter require further research. With regard to standpoint theory, it would be worthwhile to examine the process of constructing codes and indicators of good governance and the dialogues of sport directors (in terms of tasks, responsibilities and behaviours) that construct them, since these may reproduce or change existing power relations, including their impact on sport.

Similarly, how might a person's position on a board (in terms of gender, race, validity, sexual orientation, etc.) impact how an ethics of care is implemented in sport boards. Where, when, why and how do sport boards deal with 'different voices' in their governance for example, and how does this contribute to inclusion or exclusion in sport? Further research into the meaning of standpoints and ethics of care, will provide a better insight into the value of these feminist perspectives for practicing and theorising good governance in sport.

\section{Implications for practitioners}

Applying an ethics of care means not only listening to and actually hearing the standpoints or perspectives of those marginalised but also making decisions based on favouring the least advantaged members of the community and ensuring they are unharmed by the consequences of decisions. This implies that practitioners or policy makers need to see athletes, participants, stakeholders, colleagues in the organisation as individuals, with their own needs and as part of a wider web of relationships with friends and relatives. It means that those involved in sport governance need to recognise and reflect on their own role as providers and 
facilitators of opportunities for sport participation and governance and also their role as agents that contribute to the well-being of a (sport) community.

Practicing a feminist perspective on good governance is about developing critical self-reflection on personal positionality and understanding multiple points of view of policy makers and others involved in doing good governance. Dialogical relations are therefore, crucial for gaining insight in the heterogeneity of knowledge (Collins 1990). Collins argues that a dialogue between people of different positions is the only way to "approximate truth". It facilitates an ability to imagine or understand each other's standpoints, although without owning them. Another standpoint theorist, Elsa Barkley Brown (1989) is convinced that: "All people can learn to center in another experience, validate it, and judge it by its own standards without the need of comparison or the need to adopt that framework as their own. In such dialogues, 'one has no need to 'decenter' anyone in order to center someone else; one has only to constantly, appropriately, 'pivot the center"' (Brown 1989, p. 922).

According to Collins (1990), dialogue as an approach is essential to reform partial knowledge into shared knowledge and to ensure marginalised groups have a place in society. In a democratic society, that is precisely the job of those responsible for realising (the creation and implementation of) good governance. This does not only mean conducting relevant dialogues, but also to embedding the representation of marginalised groups in bodies that construct and express good governance in organisations. In such organisations mutual and contextual relationships between stakeholders pivot around the care for each other, instead of focusing on their own achievements and interests and ensuring these are met through competitive negotiations. If this succeeds, ethics of care is no longer an individual practice, but is embedded in the structure of organisations as part of good governance.

\section{References}

Baier, A 1994, Moral Prejudices: Essays on Ethics, Harvard University Press, Cambridge, MA.

Bartky, SL 1990, Femininity and Domination Studies in the Phenomenology of Oppression, Routledge, New York.

Benhabib, S 1992, Situating the Self: Gender, Community and Postmodernism in Contemporary Ethics, Polity Press, Oxford.

Broughton, JM 1983, 'Women's Rationality and Men's Virtues: A Critique of Gender Dualism in Gilligan's Theory of Moral Development', Social Research, vol. 50, no. 3, pp. 597-642.

Brown, EB 1989, 'African-American Women's Quilting: A Framework for Conceptualizing and Teaching African-American Women's History', Signs, vol. 14, no. 4, pp. 921-29. doi:10.1086/494553

Collins, PH 1990, Black Feminist Thought: Knowledge, Consciousness, and the Politics of Empowerment, Unwin Hyman, Boston.

Collins, PH 1997, 'Comment on Hekman's "Truth and Method: Feminist Standpoint Theory Revisited”: Where's the Power', Journal of Women in Culture and Society, vol. 22, no. 2, pp. 375-81. doi:10.1086/495161 
Connell, E (eds) 2009, Gender. Short Introductions, Polity Press, Cambridge.

Davis, KE, Kingsbury, B \& Merry, SE 2015, 'Introduction: The Local-Global Life of Indicators: Law, Power, and Resistance' in SE Merry, B Kingsbury \& K Davis (eds), The Quiet Power of Indicators. Measuring Governance Corruption and Rule of Law, Cambridge University Press, Cambridge, pp. 1-26. doi:10.1017/CBO9781139871532.001

Debognies, P, Schaillée, H, Haudenhuyse, R \& Theeboom, M 2019, 'Personal Development of Disadvantaged Youth Through Community Sports: A Theory-Driven Analysis of Relational Strategies', Sport in Society, vol. 22, no. 6, pp. 897-918. doi:10.1080/ 17430437.2018.1523144

Dowling, M, Leopkey, B \& Smith, L 2018, 'Governance in Sport: A Scoping Review', Journal of Sport Management, vol. 32, no. 5, pp. 438-51. doi:/10.1123/jsm.2018-0032

Gilligan, C 1982, In a Different Voice: Psychological Theory and Women's Development, Harvard University Press, Cambridge, MA.

Greeno, CC \& Maccoby, EE 1986, 'How Different Is the 'Different Voice'?', Signs, vol. 11, no. 2, pp. 310-16. doi:10.1086/494223

Grimshaw, J 1986, Philosophy and Feminist Thinking, Minnesota University Press, Minneapolis, MN.

Haraway, D 1991, 'A Cyborg Manifesto: Science, Technology, and Socialist-Feminism in the Late Twentieth Century', in D Haraway, Simians, Cyborgs and Women: The Reinvention of Nature, Routledge, New York, pp. 149-81.

Harding, S (eds) 2004, The Feminist Standpoint Theory Reader, Routledge, New York.

Hartsock, NCM 1983, 'The Feminist Standpoint: Developing the Ground for a Specifically Feminist Historical Materialism' in NCM Hartsock Discovering Reality: Feminist Perspectives on Epistemology, Metaphysics, Methodology, and Philosophy of Science, Springer, Dordrecht, pp. 283-310. doi:10.1007/0-306-48017-4_15

Hekman, S 1997, 'Truth and Method: Feminist Standpoint Theory Revisited', Journal of Women in Culture and Society, vol. 22, no. 2, pp. 341-65. doi:10.1086/495159

Held, V 1993, Feminist Morality: Transforming Culture, Society, and Politics, University of Chicago Press, Chicago.

Held, V 2006, The Ethics of Care: Personal, Political, and Global, Oxford University Press, Oxford.

Henry, I \& Lee, C 2004, 'Governance and Ethics in Sport', in S Chadwick \& J Beech (eds), The Business of Sport Management, Pearson Education, Harlow, pp. 25-41.

Kittay, EF 1999, Love's Labor: Essays on Women, Equality and Dependency, Routledge, New York.

Knoppers, A \& McLachlan, F 2018, 'Reflecting on the Use of Feminist Theories in Sport Management Research', in L Mansfield, J Caudwell, B Wheaton \& B Watson (eds), The Palgrave Handbook of Feminism and Sport, Leisure and Physical Education, Palgrave Macmillan, London, pp. 163-80.

Machold, S, Ahmed, PK \& Farquhar, SS 2008, 'Corporate Governance and Ethics: A Feminist Perspective', Journal of Business Ethics, vol. 81, no. 1, pp. 665-78. doi:10.1007/ s10551-007-9539-5

Merry, SE, Davis, KE \& Kingsbury, B 2015, The Quiet Power of Indicators. Measuring Governance Corruption and Rule of Law, Cambridge University Press, Cambridge. doi:10.1017/CBO9781139871532

Morrell, K 2006, 'Governance, Ethics and the National Health Service', Public Money and Management, vol. 26, no. 1, pp. 55-62.

Noddings, N 1984, Caring: A Feminine Approach to Ethics and Moral Education, University of California Press, Berkeley. 
Parent, MM \& Hoye, R 2018, 'The Impact of Governance Principles on Sport Organisations' Governance Practices and Performance: A Systematic Review', Cogent Social Sciences, vol. 4, no. 1. doi:10.1080/23311886.2018.1503578

Puwar, N 2004, Space Invaders. Race, Gender and Bodies Out of Place, Berg, Oxford/New York.

Rosenberg, A (ed.) 2016, Philosophy of Social Science, Westview Press, Boulder.

Sevenhuijsen, S 2003, 'The Place of Care: The Relevance of the Feminist Ethic of Care for Social Policy',Feminist Theory, vol.4, no.2,pp.179-97.doi:10.1177/14647001030042006

Smith, D 1987, The Everyday World as Problematic: A Feminist Sociology, Northeastern University Press, Boston.

Smith, D 1990, The Conceptual Practices of Power: A Feminist Sociology of Knowledge, Northeastern University Press, Boston.

Smith, D 1997, 'Comment on Hekman's "Truth and Method: Feminist Standpoint Theory Revisited"', Signs: Journal of Women in Culture and Society, vol. 22, no. 2, pp.392-398. doi:10.1086/495164

Steward, TJ 2020, 'Capitalism and the (il)Logics of Higher Education's COVID-19 Response: A Black Feminist Critique', Leisure Sciences, vol. 43, no. 1-2, pp. 260-66. doi: 10.1080/01490400.2020.1774011

Stoetzler, M \& Yuval-Davis, N 2002, 'Standpoint Theory, Situated Knowledge and the Situated Imagination', Feminist Theory, vol. 3, no. 1, pp. 315-33. doi:10.1177/ 146470002762492024

Surie, G \& Ashley, A 2008, 'Integrating Pragmatism and Ethics in Entrepreneurial Leadership for Sustainable Value Creation', Journal of Business Ethics, vol. 81, no 1, pp. 235-46. doi:10.1007/s10551-007-9491-4

Tronto, JC 1987, 'Beyond Gender Difference to a Theory of Care', Signs, vol. 12, no. 1, pp. 644-63. doi:10.1086/494360

Tronto, JC 1993, Moral Boundaries: A Political Argument for an Ethic of Care, Routledge, New York.

Tong, R 1993, Feminine and Feminist Ethics, Wadsworth Publishing Company, Belmont.

Tong, R (ed.) 2009, Feminist Thought: A More Comprehensive Introduction, Westview Press, Boulder.

Weeks, K 1998, Constituting Feminist Subjects, Cornell University Press, Ithaca, NY.

Yuval-Davis, N 2011, Power, Intersectionality and the Politics of Belonging, FREIA - Feminist Research Center, Aalborg. 